\title{
AN EMPIRICAL MODEL FOR ADSORPTION THERMODYNAMICS OF COPPER (II) FROM SOLUTIONS ONTO ILLITE CLAY-BATCH PROCESS DESIGN
}

\author{
*BAYBARS ALI FIL, AND MUSTAFA KORKMAZ, CENGIZ ÖZMETIN
}

${ }^{2}$ Balıkesir University, Department of Environmental Eng., 10145 Çă̆lş, Balıkesir, Turkey

\begin{abstract}
The copper causes important health problems risk when it exists at high concentrations in drinking waters and daily feeds. Therefore, in this study, copper adsorption from solutions onto illite clay was investigated in batch mode as a function of the initial solution $\mathrm{pH}(3-6)$, temperature (30-60 $\left.{ }^{\circ} \mathrm{C}\right)$ and ionic strength $\left(0-0.1 \mathrm{~mol} / \mathrm{L}^{-1} \mathrm{NaCl}\right)$. The equilibrium was attained within 24 hours. Optimum conditions were determined as $\mathrm{pH} 6$, temperature $60{ }^{\circ} \mathrm{C}$ and $0 \mathrm{~mol} / \mathrm{L}^{-1} \mathrm{NaCl}$ concentration. The isotherm data followed the S-class isotherm. The reason of this S-class isotherm was either solute-solute attractive forces at the surface causing cooperative adsorption or a competing reaction such as complexation with a ligand. Mathematically, the isotherm data were explained with the sum of several single Freundlich models. Also, the thermodynamic parameters of the process were calculated. Positive values of Gibbs free energy change $\left(\Delta \mathrm{G}^{\circ}\right)$ indicated that the adsorption process was unspontaneous. As the enthalpy change $\left(\Delta \mathrm{H}^{\circ}\right)$ had positive value for all the parameter intervals, copper adsorption was concluded to be physical and endothermic process. The positive entropy values indicated that the randomness at solid-liquid interface increased with concentration decrease. Maximum copper adsorption capacity of illite clay was calculated at $60^{\circ} \mathrm{C}$ as $1.823 \times 10^{-5} \mathrm{~mol} / \mathrm{g}$. Furthermore, an empirical model was developed to determine the thermodynamic parameters of the process and operation conditions of the batch reactor as follows.
\end{abstract}

Keywords: Copper, illite, S-shaped isotherm, thermodynamics, empirical model

\section{INTRODUCTION}

The copper is most commonly present in the earth's crust as chalcopyrite $\left(\mathrm{CuFeS}_{2}\right)$, bornite $\left(\mathrm{CusFeS}_{4}\right)$ and chalcocite $\left(\mathrm{Cu}_{2} \mathrm{~S}\right)^{1}$. The metallic copper and copper compounds are widely used in many industries such as the petroleum, copper brass, copper ammonium rayon, battery, fertilizer, dye and pigment 2, 3 . Copper is non-biodegradable and persistently accumulates in the food chain and therefore its removal from wastewaters is necessary ${ }^{4}$. As the soil components such as clays and organic acids bond the copper strongly ${ }^{5}$, it is difficult to wash out the copper from contaminated soils. Copper is a toxic and mutagenic element for humans and causes brain, skin, pancreas and hearth diseases ${ }^{3}$. Copper limit value for drinking water and wastewater discharge is proposed as $1.3 \mathrm{mg} / \mathrm{L}^{2,6}$. Also, maximum copper concentration for irrigation waters is recommended as $0.2 \mathrm{mg} / \mathrm{L}^{6}$. It is possible to reduce the copper below limit values with the physico-chemical methods such as chemical precipitation ${ }^{7}$, electrocoagulation ${ }^{8}$, adsorption ${ }^{9,10}$, ion exchange ${ }^{11}$, biosorption ${ }^{12,13}$ and membrane filtration after complexation ${ }^{14}$. But, the treatment cost plays a restrictive role in the application of these methods, and therefore cost-effective methods are needed.

The obtained results from the adsorbent investigations in the last two decades have made the adsorption technology one of the cost-effective methods for wastewater treatment. Although the activated carbon is one of the most effective adsorbent against heavy metals, it requires chelating agents to enhance its performance, and therefore its use is expensive ${ }^{3}$. Most of the clays minerals have satisfying adsorption capacity as well as their low price ${ }^{15}$. For this reason, the clay minerals can be shown as a suitable alternative to the activated carbons. The World clay reserves have been calculated as 81,870 million tones ${ }^{15}$. Clay minerals are classified in several subgroups under planar hydrous phyllosilicates and non-planar hydrous phyllosilicates. Illite clay belonging to the mica group of planar hydrous phyllosilicates is a $2: 1$ layered mineral ${ }^{16}$. Illite clay is formed from one octahedral alumina layer that is interfered two tetrahedral silica layers. Two unit illite layers are bounded to each other by potassium cations. The potassium cations hinder the water entering to between two illite layers and therefore, illite clay cannot swell in the aqueous suspensions ${ }^{17}$.

Although the illite is found abundantly in nature ${ }^{18}$, the studies showing the use of illite for heavy metal adsorption are limited. The reported studies have showed that illite mineral has a strong affinity towards heavy metal cations ${ }^{3}$ 18,19. Alvarez and coworkers studied the adsorption of copper on illite and the isotherm data were explained by the sum of the several single Langmuir and
Freundlich models ${ }^{20}$. In several studies, a constant capacitance model was used to describe the metal adsorption mechanism onto illite surface ${ }^{18,19}$. Turan and coworkers developed a linear model for the copper and zinc adsorption onto illite surface using $2^{3}$ factorial experimental designs ${ }^{3}$. Also, a multi-site model based on the use of the surface functional groups such as $\equiv \mathrm{SiOH}, \equiv \mathrm{AlOH}$, $\equiv \mathrm{SiO}^{-}$ and $\equiv \mathrm{AlO}^{-}$was reported to describe metal adsorption onto illite surface ${ }^{21}$. The models reviewed in this study are related with only mechanism description for heavy metal adsorption onto illites, but no of them is useful in operation and design of a batch reactor. Furthermore, most of the reported models contain many fitting parameters making them complex to use as practically.

In this study, we aimed to develop an empirical model that is useful in design a batch reactor and calculation of the process thermodynamics. For this purpose, the effects of $\mathrm{pH}$, temperature and ionic strength on copper adsorption onto illite clay were investigated. The isotherm analysis of the data was done using Giles isotherm classification and data fitted the S-class isotherm. The S-class isotherm could be described as mathematically. The provided mathematical model was used in development of the empirical model. Also, thermodynamic parameters of the copper-illite process under changing $\mathrm{pH}$, temperature and ionic strength effect were calculated and discussed.

\section{EXPERIMENTAL PROCEDURE}

\subsection{Illite Clay}

The used illite sample was collected from a deposit in Ünye-Ordu in Turkey. The X-Ray Diffraction (XRD) pattern of the illite sample was given in Figure 1. The chemical analysis results of illite sample were as follows: $\mathrm{SiO}_{2}(45.67 \%), \mathrm{Al}_{2} \mathrm{O}_{3}(36.88 \%), \mathrm{K}_{2} \mathrm{O}(8.9 \%), \mathrm{MnO}(0.82 \%), \mathrm{F}(0.64 \%), \mathrm{Na}_{2} \mathrm{O}$ $(0.31 \%), \mathrm{H}_{2} \mathrm{O}(6.78 \%)$. Illite sample was dried at $103{ }^{\circ} \mathrm{C}$ during 24 hours in a furnace and sieved to $45-90 \mu \mathrm{m}$ particle size fractions before being used. The structural block of the illite was given in Figure 2.

\subsection{Adsorption Studies}

The experimental parameters and their intervals were given in Table 1 . All the studied solution concentrations were prepared from the stock solution having a copper concentration of $1.5738 \times 10^{-3} \mathrm{~mol} / \mathrm{L}$. Copper solutions were prepared using copper chloride, $\mathrm{CuCl}_{2} \cdot 2 \mathrm{H}_{2} \mathrm{O}$. An automatic pipette was used for concentration adjustment. The solid-to-solution ratio for each experiment was $0.25 \mathrm{~g} / 50 \mathrm{~mL}$. Solution $\mathrm{pH}$ levels were adjusted by appropriate droplets of diluted acid $(\mathrm{HCl})$ and base solutions $(\mathrm{NaOH})$. A pH meter was used for $\mathrm{pH}$ measurements (WTW, Germany). The ionic strength of the solutions was adjusted with appropriate volumes of $1 \mathrm{~mol} / \mathrm{L} \mathrm{NaCl}$ solution. The experiments 
were carried out in batch mode using a temperature controlled incubator shaker (ZHICHENCG, China). The experimental procedure was as follows: Firstly, a desired concentration of copper solution was prepared as $50 \mathrm{~mL}$ and the $\mathrm{pH}$ of the solution was adjusted and the weighted amount of illite was added to the solution and finally the prepared solution was reacted in a temperature controlled incubator shaker. After reaction, $10 \mathrm{~mL}$ solutions were centrifuged at 10,000 rpm during $5 \mathrm{~min}$ and $5 \mathrm{~mL}$ solutions taken for dilutions. The diluted copper solutions were analyzed at $324.7 \mathrm{~nm}$ using an atomic absorption spectrometer (AAS) (UNICAM, England). The samples were automatically measured three times in one aspiration by the AAS. The relative standard deviation (RSD) for the used AAS was generally in the range of $0-3 \%$. The flame type of the AAS was air-acetylene. Standard solutions prepared for calibration curve had a concentration range of $0-10 \mathrm{mg} / \mathrm{L}$. A mass balance equation was used to calculate the adsorption capacity of illite as follows.

$$
Q_{e}=\left(\left(C_{0}-C_{e}\right) \times V / W\right)
$$

Where, $C_{o}$ and $C_{e}$ are the solution copper concentrations at initial and equilibrium (mol/L). $\stackrel{e}{Q}$ is the adsorption capacity at equilibrium $(\mathrm{mol} / \mathrm{g}) . V$ is the solution volume (L). $W$ is the mass of illite added to the solutions $(\mathrm{g})$.

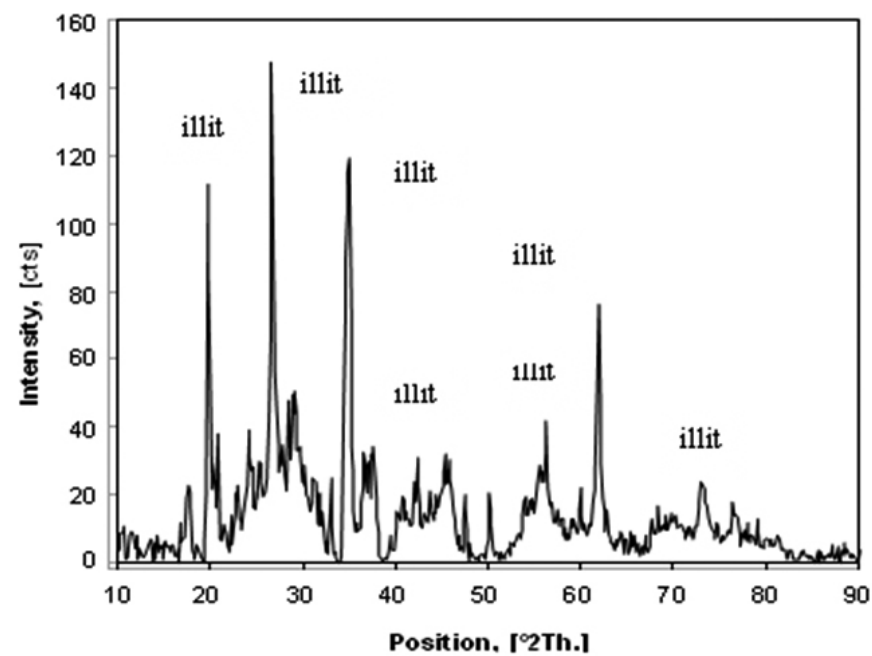

Figure 1: XRD pattern of illite clay

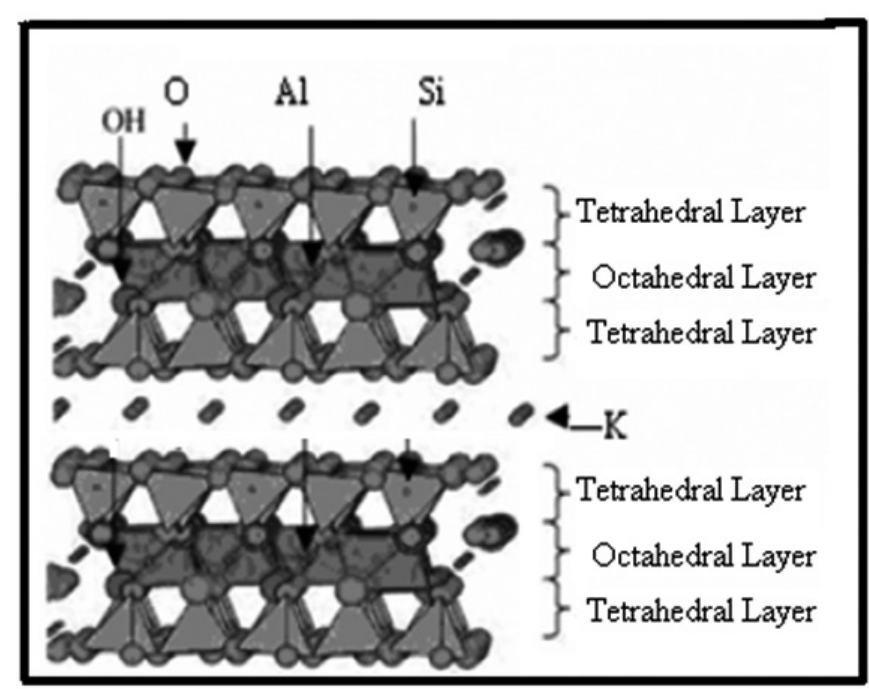

Figure 2: Block structure of illite mineral
Table 1: The intervals of experimental parameters.

\begin{tabular}{|c|c|}
\hline Parameters & Value \\
\hline $\mathrm{pH}$ & $3,4,5.14,6$ \\
\hline Temperature, ${ }^{\circ} \mathrm{C}$ & $30,40,50,60$ \\
\hline Ionic Strength, $\mathrm{M}$ & $0,0.001,0.01,0.10$ \\
\hline Concentration, $\mathrm{M}$ & $1.574-18.884 \times 10^{-5}$ \\
\hline Solid-to-solution ratio, $\mathrm{g} / 50 \mathrm{~mL}$ & 0.25 \\
\hline Agitation Speed, $\mathrm{rpm}$ & $150 \mathrm{rpm}$ \\
\hline Equilibrium Time, $\mathrm{h}$ & 24 \\
\hline
\end{tabular}

\section{RESULTS AND DISCUSSION}

In this study, copper adsorption onto illite clay was investigated as a function of solution $\mathrm{pH}$, temperature and ionic strength. Furthermore, an empirical model that enables to calculate the thermodynamic parameters and operation conditions of the batch process was developed.

\subsection{Effect of Parameters}

3.1 Effect of $\mathbf{p H}$

Solution $\mathrm{pH}$ level significantly effects cation adsorption onto clays because it determines the surface charge ${ }^{17}$. Also, ionization degree of the cations is depended on the solution $\mathrm{pH}$ level ${ }^{18,22}$. The effect of initial $\mathrm{pH}$ on copper adsorption onto illite was studied at $\mathrm{pH}$ range of 3-6 and other parameters were kept constant. The results were given in Figure 3. When the solution $\mathrm{pH}$ was increased from 3 to 6 , the capacity of the illite increased from 1.185 to $1.698 \times 10^{-5} \mathrm{~mol} / \mathrm{g}$. This result was attributed to that the surface of the illite mineral became negative at high $\mathrm{pHs}$ and thereby the capacity increased. On the other hand, the competitive adsorption occurred between hydrogen ions and copper for fixation sites on illite surface and hence capacity decreased at low $\mathrm{pHs}{ }^{23}$. Similar $\mathrm{pH}$ effect was reported for cation adsorption onto illite clay ${ }^{3,18}$ and Alvarez-Puebla and coworkers reported that copper adsorption increased with $\mathrm{pH}$ increase of solution ${ }^{20}$. Also, Gu and coworkers reported two distinct mechanisms for metal adsorption onto illite: (i) nonspecific ionexchange reaction occurring on the $\equiv \mathrm{SiO}^{-}$and $\equiv \mathrm{AlO}^{-}$sites at low $\mathrm{pH}$ values (3-6) (ii) specific adsorption occurring on the $\equiv \mathrm{SiOH}$ and $\equiv \mathrm{AlOH}$ sites at high $\mathrm{pH}(6-9)$ values ${ }^{19}$.

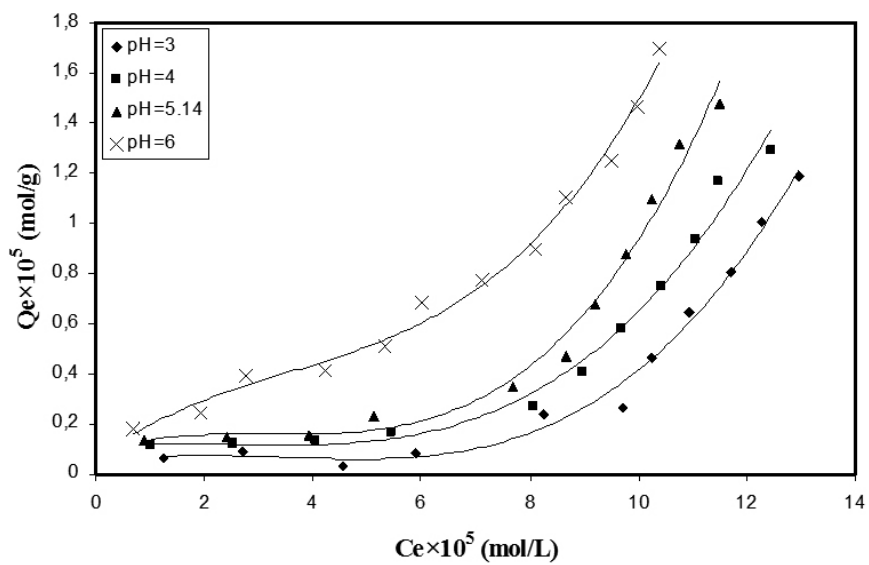

Figure 3: $\mathrm{pH}$ effect on copper adsorption (Concentration: 1.574$18.884 \times 10^{-5} \mathrm{~mol} / \mathrm{L}$, Solid-to-solution ratio: $0.25 \mathrm{~g} / 50 \mathrm{~mL}$, Temperature: $30^{\circ} \mathrm{C}$, ionic strength: $0 \mathrm{~mol} / \mathrm{L}$ )

\subsection{Effect of Ionic Strength}

Several cations such as calcium, lead, sodium and zinc can exist with copper in wastewaters. For instance, acid mine drainage contains simultaneously several different cations such as $\mathrm{Fe}^{3+}, \mathrm{Mn}^{2+}, \mathrm{Cu}^{2+}, \mathrm{Zn}^{2+}$, etc. ${ }^{24}$. In this study, sodium was selected as competitor against copper ions to study the effect of ionic strength on copper adsorption. The ionic strength of the solutions was changed from 0 to $0.1 \mathrm{~mol} / \mathrm{L} \mathrm{NaCl}$ concentration and other parameters were kept as constant. The results for sodium concentration effect were given in 
Figure 4. As can be seen in Figure 4, the copper adsorption decreased with increasing sodium concentration. This result was due to competitive adsorption of sodium cations against copper. In a study, $\mathrm{Gu}$ and coworkers studied the adsorption of $\mathrm{Cd}(\mathrm{II}), \mathrm{Cu}(\mathrm{II}), \mathrm{Ni}(\mathrm{II}), \mathrm{Pb}(\mathrm{II})$ and $\mathrm{Zn}(\mathrm{II})$ on illite at different ionic strength concentrations $\left(0.001-0.1 \mathrm{~mol} / \mathrm{L}^{-1} \mathrm{NaNO}_{3}\right){ }^{19}$. Similarly, $\mathrm{Gu}$ and coworkers reported that adsorbed amount of all the cations increased when the ionic strength was decreased ${ }^{19}$. Özmetin et. al. also reported that copper adsorption capacity of illite clay decreased with increasing ionic strength as the competitor sodium cations occupied more binding sites ${ }^{15}$.

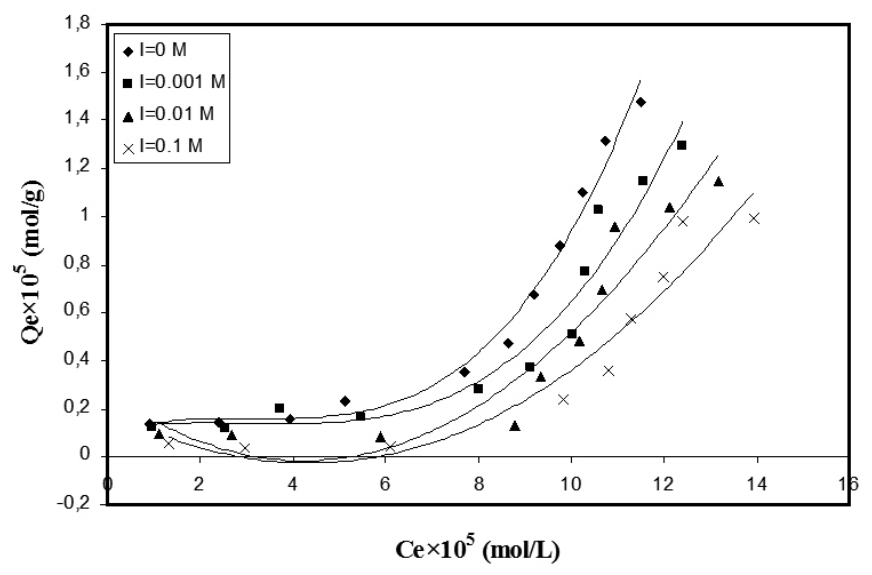

Figure 4: Ionic strength effect on copper adsorption (Concentration: $1.574-18.884 \times 10^{-5} \mathrm{~mol} / \mathrm{L}$, Solid-to-solution ratio: $0.25 \mathrm{~g} / 50 \mathrm{~mL}$, Temperature: $30{ }^{\circ} \mathrm{C}$, pH: 5.14 (natural))

\subsection{Effect of Temperature}

The results for temperature effect in copper adsorption onto illite were given in Figure 5. As can be seen in Figure 5, when the solution temperature was increased from 30 to $60^{\circ} \mathrm{C}$, the capacity of illite increased from 1.476 to $1.823 \times 10^{-5} \mathrm{~mol} / \mathrm{g}$. The high temperatures made the copper ions more energetic to react with surface sites ${ }^{25}$. On the other hand, the high temperatures decreased the viscosity of the solution and this resulted in easily diffusion of copper ions through the external liquid film layer surrounding the illite particle ${ }^{26,27}$. The copper adsorption onto illite was endothermic reaction because the high temperatures increased the capacity. Similar temperature effect was reported in the adsorption of cationic methyl violet and methylene blue dyes on illite surfaces ${ }^{15,17}$.

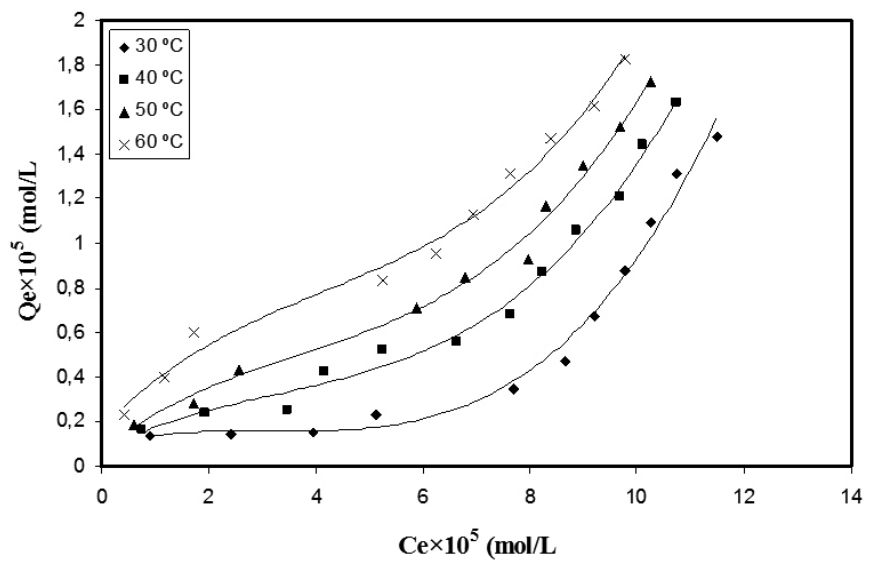

Figure 5: Temperature effect on copper adsorption (Concentration: 1.574$18.884 \times 10^{-5} \mathrm{~mol} / \mathrm{L}$, Solid-to-solution ratio: $0.25 \mathrm{~g} / 50 \mathrm{~mL}, \mathrm{pH}: 5.14$ (natural), ionic strength: $0 \mathrm{~mol} / \mathrm{L}$ )

\subsection{Adsorption Isotherm for Copper Adsorption}

The isotherm data fitted the S-class isotherm reported by Giles and coworkers. ${ }^{28}$. The reason of this S-class isotherm was either solute-solute attractive forces at the surface causing cooperative adsorption or a competing reaction such as complexation with a ligand ${ }^{29}$. The isotherm data given in
Figure 3-5 were explained by the sum of several single Freundlich models and the model equation was given in below.

$$
Q_{e}=X_{1} C_{e}^{3}+X_{2} C_{e}^{2}+X_{3} C_{e}^{1}+X_{4} C_{e}^{0}
$$

Where, $Q_{e}$ is maximum adsorption capacity at equilibrium (mol $\left./ \mathrm{g}\right) . C_{e}$ is equilibrium solution concentration (mol/L). $X_{1}, X_{2}, X_{3}$ and $X_{4}$ are equation constants.

The coefficient of determination values for the suggested model (Eq.2) were given in Table 2. As can be seen in Table 2, the coefficients of determination values have acceptable importance (0.984-0.998).

Table 2: The fitness of adsorption data to the proposed model.

\begin{tabular}{|c|c|c|c|}
\hline \multicolumn{3}{|c|}{ Parameters } & Model \\
\hline Temperature & $\begin{array}{c}\text { Ionic } \\
\text { strength }\end{array}$ & $\mathbf{p H}$ & $Q_{e}=X_{1} C_{e}{ }^{3}+X_{2} C_{e}{ }^{2}+X_{3} C_{e}{ }^{1}+X_{4} C_{e}{ }^{0}$ \\
\hline 30 & 0 & 5.14 & 0.9961 \\
\hline 40 & 0 & 5.14 & 0.9959 \\
\hline 50 & 0 & 5.14 & 0.9971 \\
\hline 60 & 0 & 5.14 & 0.9953 \\
\hline 30 & 0.001 & 5.14 & 0.9848 \\
\hline 30 & 0.01 & 5.14 & 0.9837 \\
\hline 30 & 0.1 & 5.14 & 0.9839 \\
\hline 30 & 0 & 3 & 0.9957 \\
\hline 30 & 0 & 4 & 0.9961 \\
\hline 30 & 0 & 6 & 0.9977 \\
\hline
\end{tabular}

3.5. Developed Empirical Model for Process Thermodynamics

To improve an empirical model that is useful for determination of optimum design parameters of a batch reactor using the Eq. (2), the isotherm data were analyzed with Statistica 7.0 programme. In the analysis of data set 107 items of experimentally obtained data were put into analysis. In the analysis, non-linear estimation section of the programme was used for specific regression analysis. . It was thought that the constants $X_{1}, X_{2}, X_{3}$ and $X_{4}$ would represent the effects of parameters such as $\mathrm{pH}$, temperature and ionic strength. Therefore these constants $\left(X_{1}, X_{2}, X_{3}\right.$ and $\left.X_{3}\right)$ were replaced with $\mathrm{pH}$, temperature and ionic strength in the model. Also, equilibrium solution concentration values $\left(C_{e}\right)$ in Eq.(2) were replaced with the initial concentration term $\left(C_{0}\right)$ in the model to make the model more useful. The developed empirical model was as follow.

$Q_{e}=492.148 \times 10^{-3} \times T^{-2.20209} \times\left[H^{+}\right]^{-0.197171} \times[I]^{-0.626829} \times\left[C_{0}\right]^{-0.541706}+18.38426 \times T^{2.930212} \times\left[H^{+}\right]^{0.019003}$ $\times[I]^{-0.034157} \times\left[C_{0}\right]^{2.276633}-1.327354 \times 10^{-16} \times T^{6.291894} \times\left[H^{+}\right]^{-0.613007} \times[I]^{82.98830} \times\left[C_{0}\right]^{0.413969}$

Where, $Q_{e}$ is the model response for the adsorption capacity $(\mathrm{mol} / \mathrm{g})$. $\left[\mathrm{H}^{+}\right]$is molar concentration of hydrogen ions $(\mathrm{mol} / \mathrm{L}) . T$ is temperature $(\mathrm{K})$. [I] is molar concentration of sodium ions in the solution $(\mathrm{mol} / \mathrm{L}) . C_{0}$ is initial concentration of copper in the solution $(\mathrm{mol} / \mathrm{L})$. The plot for (Qe,experimental) versus $(Q e$,predicted) was given in Figure 6 and coefficient of determination value of the plot was 0.9823 .

The thermodynamic analysis of the adsorption data gives information about the spontaneity and nature of the adsorption process. The Gibbs free energy change is a function of equilibrium constant, enthalpy and entropy as follows ${ }^{29}$.

$$
\begin{gathered}
\Delta \mathrm{G}^{\mathrm{o}}=-\mathrm{RT} \ln K d \\
\Delta \mathrm{G}^{\mathrm{o}}=\Delta \mathrm{H}^{\mathrm{o}}-\mathrm{T} \Delta \mathrm{S}^{\mathrm{o}}
\end{gathered}
$$

If two equations given above are combined, we get

$$
\operatorname{lnKd}=-\Delta \mathrm{G}^{\mathrm{o}} / \mathrm{RT}=\Delta \mathrm{S}^{\mathrm{o}} / \mathrm{R}-\Delta \mathrm{H}^{\mathrm{o}} / \mathrm{RT}
$$


Where, $\Delta G^{o}$ is the free energy change $(\mathrm{kJ} / \mathrm{mol}) . \Delta H^{o}$ is the enthalpy change $(\mathrm{kJ} / \mathrm{mol}) . \Delta S^{o}$ is the entropy change $(\mathrm{kJ} / \mathrm{mol} \mathrm{K}) . K_{d}=\left(Q_{e} / C\right)$ is the equilibrium constant $(\mathrm{L} / \mathrm{g}) . T$ is absolute temperature $(\mathrm{K})$ and $R$ is the universal gas constant $(8.314 \mathrm{~J} / \mathrm{mol} \mathrm{K})$. Thus $\Delta H^{\circ}$ and $\Delta S^{\circ}$ can be determined from the slope and intercept of the linear Eq. (6) respectively.

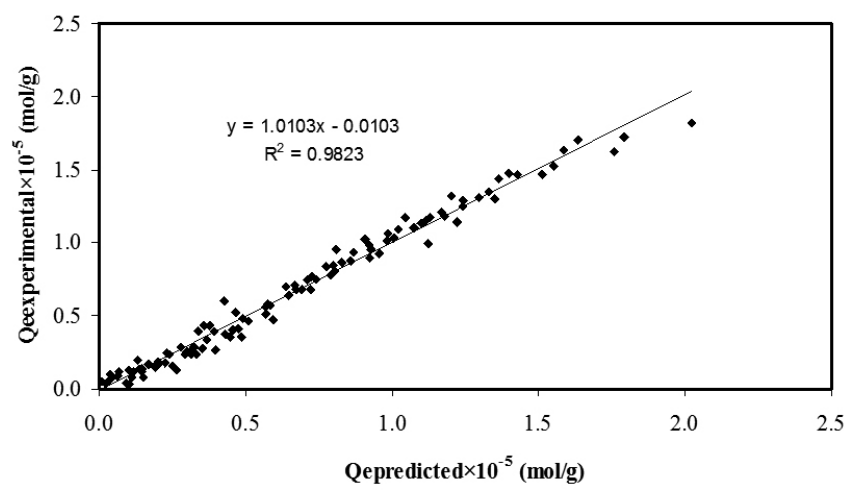

Figure 6: The plot for Qe,experimental versus Qe,predicted

The results of thermodynamic analysis were given in Table 3. Positive value of enthalpy $\left(\Delta \mathrm{H}^{\circ}\right)$ indicated that the process had endothermic nature. While the enthalpy range for physical adsorption is between -20 to $-40 \mathrm{~kJ} /$ $\mathrm{mol}$, this value for chemisorption is between -400 and $-80 \mathrm{~kJ} / \mathrm{mol}^{30}$. The enthalpy change values were in the range of 10.327 and $61.790 \mathrm{~kJ} / \mathrm{mol}$. The positive value of enthalpy indicated that copper adsorption was physical in nature. Although the process was physical in nature, the capacity of the illite increased with temperature increase. This result was attributed to the increasing vibration energy of copper ions to react with illite at high temperatures. In the $\mathrm{pH}$ effect section, the mechanism given based on initial $\mathrm{pH}$ value was nonspecific ion exchange reaction, and therefore in respect to enthalpy value the ion exchange reaction is generally between physical adsorption and chemical sorption. But the mechanism was found as physical adsorption in our study based on thermodynamic investigation. Because $\Delta \mathrm{H}$ values were found in the range of 10.327 and $61.790 \mathrm{~kJ} / \mathrm{mol}$. We considered that the physical adsorption was dominant in copper adsorption because the isotherm shape of copper adsorption onto illite indicates that solid-solid attractive forces were dominant in copper adsorption indicating physical adsorption. Also, the free energy change $\left(\Delta G^{\circ}\right)$ had positive value for all the parameter intervals and the process was concluded to be unspontaneous. Adsorption-desorption rate at solid-solution interface decreased due to decreasing entropy change with increasing concentration (Table 3 ). This result was due to the increasing solutesolute attractive forces which increased the copper adsorption onto surface and decreased the adsorption-desorption rate ${ }^{29}$. The developed model given in Eq. 3 was also found as useful for calculation of thermodynamic parameters of the process for a given experimental condition by replacing $K_{d}$ value with the response $Q_{e}$ and by dividing the model to the $C_{e}$ value. The developed thermodynamic model was given in below.

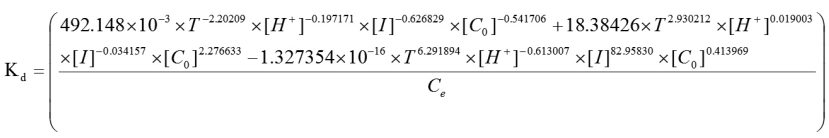

Where, $K_{d}=(Q / C)$ is the equilibrium constant $(\mathrm{L} / \mathrm{g}) . Q_{e}$ is the model response for the adsorption capacity $(\mathrm{mol} / \mathrm{L}) . C_{e}$ is the equilibrium copper concentration $(\mathrm{mol} / \mathrm{L})$ that can be calculated by Eq. $\left.3 . \mathrm{H}^{+}\right]$is molar concentration of hydrogen ions $(\mathrm{mol} / \mathrm{L}) . T$ is temperature $(\mathrm{K})$. [I] is molar concentration of sodium ions in the solution $(\mathrm{mol} / \mathrm{L}) . C_{0}$ is initial concentration of copper in the solution $(\mathrm{mol} / \mathrm{L})$. The plot for $\left(\Delta G^{\circ}\right.$ experimental $)$ values versus $\left(\Delta G^{o}\right.$ predicted $)$ values was given in Figure 7 and coefficient of determination value was 0.9562 . In the analysis of ( $\Delta G^{o}$ experimental $)$ values versus $\left(\Delta G^{o}\right.$ predicted $)$ values 90 items of experimentally obtained data were put into analysis.

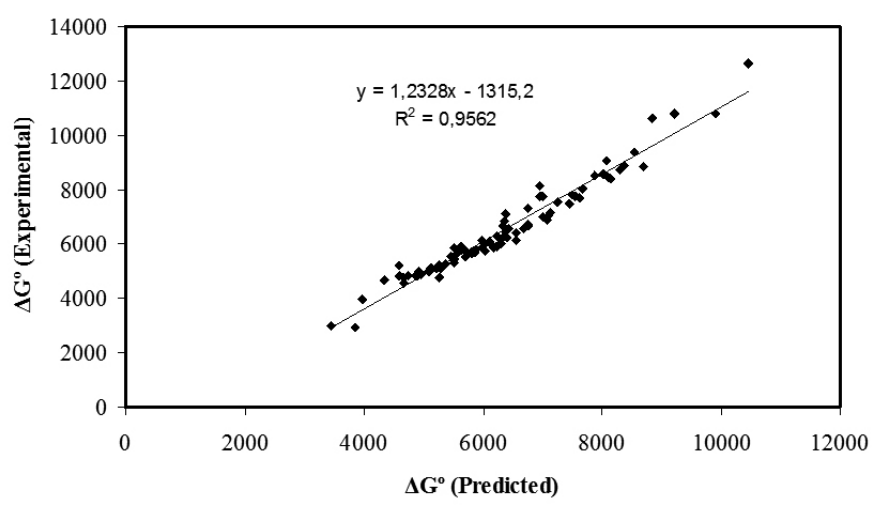

Figure 7: The plot for $\Delta G^{o}$ versus $\Delta G^{o}$

\subsection{Batch Process Design}

It is well known that the isotherm models are useful equations to design the single stage batch reactors ${ }^{31}$. For this purpose, the developed empirical model (Eq. 3) was used to design a batch reactor which was illustrated in Figure 8. The mass balance equation for the first stage of design can be given as follows.

$$
V \times\left(C_{0}-C_{e}\right)=Q_{e} \times W
$$

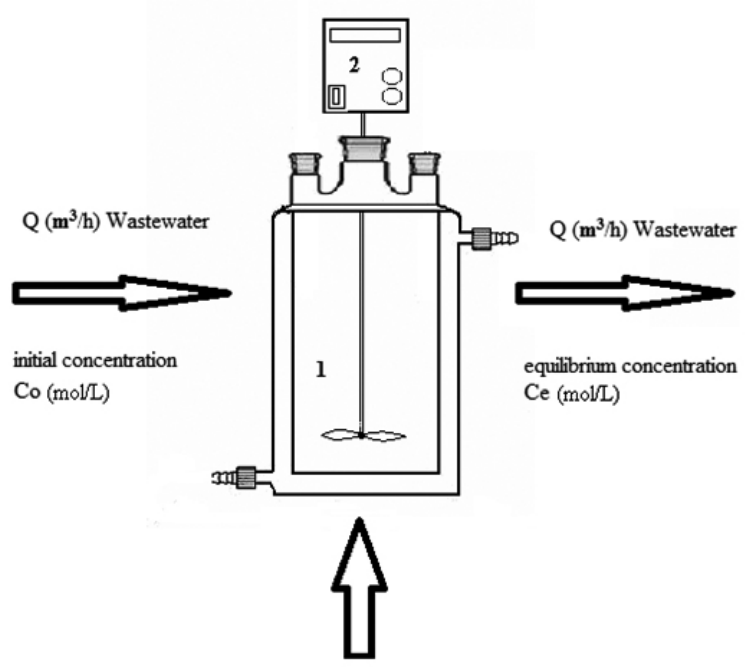

W kg Adsorbent input

Figure 8. A schematic illustration of the batch reactor

Where, $V$ is the reactor volume $\left(\mathrm{m}^{3}\right) . C_{0}$ and $C_{e}$ are the initial and equilibrium concentrations of copper in the liquid phase $(\mathrm{mol} / \mathrm{L}) . Q$ is the solid phase concentration of copper at equilibrium $(\mathrm{mol} / \mathrm{g}) . W$ is the mass of adsorbent input to the reactor $(\mathrm{kg}) . Q$ also represents the response of the developed empirical model (Eq. 3). If the equation 8 is rearranged, the final design model is obtained and can be given as follows.

$$
\begin{aligned}
\frac{W}{V}= & \frac{C_{0}-C_{e}}{492.148 \times 10^{-3} \times T^{-2.20209} \times\left[H^{+}\right]^{-0.197171} \times[I]^{-0.626829} \times\left[C_{0}\right]^{-0.541706}+18.38426 \times T^{2.930212} \times\left[H^{+}\right]^{0.019003}} \\
& \times[I]^{-0.034157} \times\left[C_{0}\right]^{2.276633}-1.327354 \times 10^{-16} \times T^{6.291894} \times\left[H^{+}\right]^{-0.613007} \times[I]^{82.95830} \times\left[C_{0}\right]^{0.413969}
\end{aligned}
$$

The plots for required mass of illite against volumes of treated wastewater were given in Figure 9. The selected parameters for model wastewater were as follow: copper concentration $18.884 \times 10^{-5} \mathrm{~mol} / \mathrm{L}, \mathrm{pH} 6$, temperature $333.15 \mathrm{~K}$, ionic strength $0.1 \mathrm{M}$. 
Table 3: The values of thermodynamic parameters as function of concentration, temperature, $\mathrm{pH}$ and ionic strength.

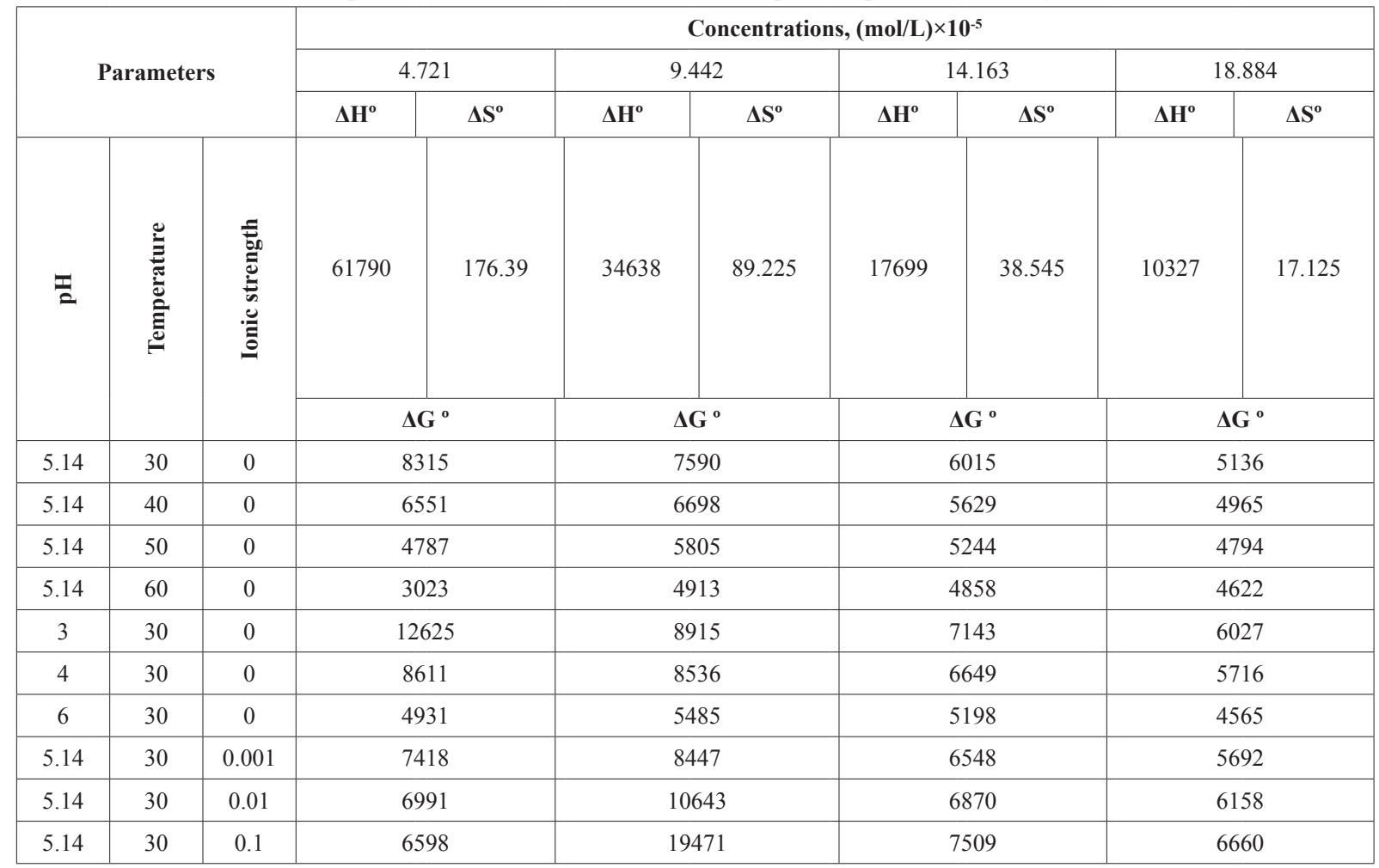

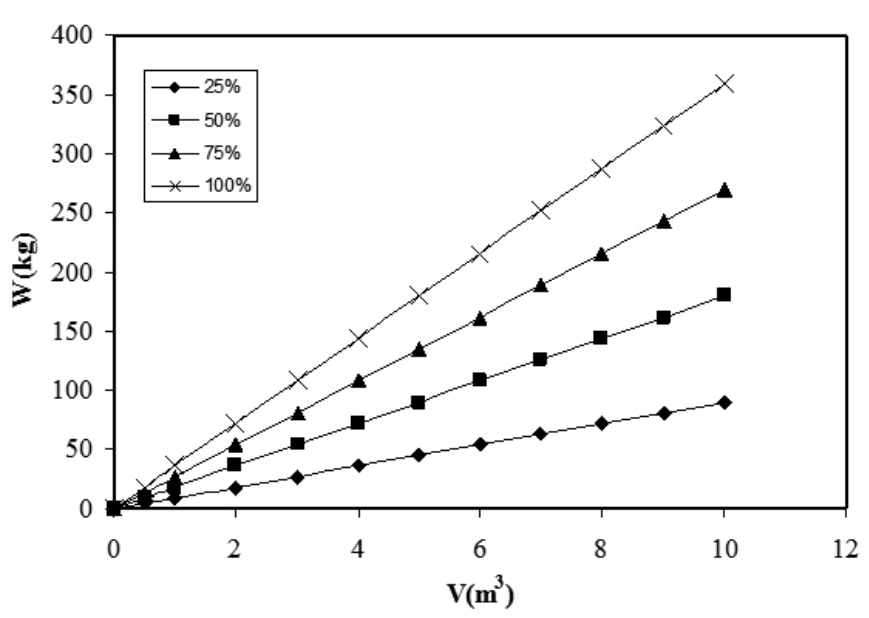

Figure 9: The plots for required masses of illite against volumes of treated wastewaters at different removal efficiencies.

\section{CONCLUSIONS}

In this study, the copper adsorption by illite clay was studied and the main results were as follows.

-The adsorption capacity of the illite increased with $\mathrm{pH}$ increase and capacity values for $3,4,5.14,6 \mathrm{pH}$ values were $1.185,1.288,1.476,1.698 \times 10^{-5}$ $\mathrm{mol} / \mathrm{g}$ respectively.

- The temperature increase raised the capacity and capacity values for 30 , $40,50,60{ }^{\circ} \mathrm{C}$ temperature values were $1.476,1.629,1.726,1.823 \times 10^{-5} \mathrm{~mol} / \mathrm{g}$ respectively.

- The ionic strength increase decreased the capacity and, capacity values for $0,0.001,0.01,0.1 \mathrm{M}$ ionic strength values were $1.476,1.296,1.143$, $0.991 \times 10^{-5} \mathrm{~mol} / \mathrm{g}$ respectively.

-The isotherm data followed the S-class isotherm. It was considered that the reason of this S-class isotherm was either solute-solute attractive forces at the surface causing cooperative adsorption or a competing reaction such as complexation with a ligand.

-The positive enthalpy values changing in the range of 10.327 and 61.790 $\mathrm{kJ} / \mathrm{mol}$ showed that the process was physical and endothermic in nature. The process was unspontaneous for all the studied parameter intervals. The adsorption desorption rate increased due to positive value of entropy increasing with decreasing concentration.

- The data could be described by the developed model at $99.1 \%$ range and the model was useful for design of the batch reactor at tested experimental conditions. Also, the developed model enabled to calculate the thermodynamics of the illite-copper process.

- The selected parameters for model wastewater to design batch process were as follow: copper concentration $18.884 \times 10^{-5} \mathrm{~mol} / \mathrm{L}, \mathrm{pH} 6$, temperature $333.15 \mathrm{~K}$, ionic strength $0.1 \mathrm{M}$. The analysis results exposed that to treat the above given wastewater having $10 \mathrm{~m}^{3}$ volume, $359.4 \mathrm{~kg}$ illite required.

- The results showed that the illite mineral would be used effectively in removal of copper from liquid wastes. The adsorption process in which the illite was used for removal of copper was considered advantageous over ion exchange, reverse osmosis, electrocoagulation, etc. because the illite is a quite cheap adsorbent.

\section{ACKNOWLEDGEMENT}

The authors are grateful for financial support of Balıkesir University Scientific Research Project Department (Project No: 2006/30)

\section{REFERENCES}

1. W. G. Davenport., M. King, M. Schlesinger, A. K. Biswas, Extractive Metallurgy of Copper vol. Fourth Edition. Oxford, U.K.: Elsevier Ltd, 2000.

2. F. Ekmekyapar, A. Aslan, Y. K. Bayhan, A. Cakici, J. Hazard. Mater. 137, 293, (2006).

3. N. G. Turan, S. Elevli, B. Mesci, Appl. Clay Sci. 52, 392, (2011).

4. S. Kocaoba, Y. Orhan, T. Akyüz, Desalination 214, 1, (2007).

5. G. Barancikova, J. Makovnikova, P. S. E. , Plant Soil Environ. 49, 565, (2003).

6. L. S. Clesceri, A. E. Greenberrg, A. D. Eaton, "Standart Methods for the 
Examination of Water and Wastewater," t. Edition, Ed., ed American Public Health Association, American Water Works Association: Water Environment Federation, 1999.

7. W. W. Eckenfelder, Industrial Water Pollution Control: the McGraw-Hill Company Companies, Inc, 2000.

8. C. Escobar, C. Soto-Salazar, M. Inés Toral, J. Environ. Manage. 81, 384, (2006).

9. C. Jeon, I. W. Nah, K.-Y. Hwang, Hydrometallurgy 86, 140, (2007).

10. W. Wu, Y. Yang, H. Zhou, T. Ye, Z. Huang, R. Liu, Y. Kuang, Water Air Soil Poll. 224, 1, (2012)

11. J. L. Valverde, A. d. Lucas, M. González, J. F. Rodríguez, J. Chem. Eng. Data 46, 1404, (2001)

12. D. Reddy, S.-M. Lee, K. Seshaiah, Water Air Soil Poll. 223, 5967, (2012).

13. M. Aryal, M. Ziagova, M. Liakopoulou-Kyriakides, Water Air Soil Poll. 223, 5119, (2012).

14. C. Cojocaru, G. Zakrzewska-Trznadel, Journal of Membrane Science 298, $56,(2007)$.

15. C. Özmetin, B. A. Fil, "The removal of organic and inorganic pollutants in water by silicate type adsorbents", Balikesir University Scientific Research Project Departament (Project No 2006/30), Balıkesir, 2006.

16. R. T. Martin, S. W. Bailey, D. D. Eberl, D. S. Fanning, S. Guggenheim, H. Kodama, D. R. Pevear, J. Srodon, F. J. Wicks, Clay Clay Miner. 39, 333, (1991).
17. E. Özmetin, "Electrokinetic properties of illite and removal of metilen blue from aqueous solutions," Phd. Thesis, Institute of Science and Technology, Ataturk University, Erzurum, 2007.

18. Q. Du, Z. Sun, W. Forsling, H. Tang, J. Colloid Interface Sci. 187, 232, (1997).

19. X. Gu, L. J. Evans, J. Colloid Interface Sci. 307, 317, (2007).

20. R. A. Alvarez-Puebla, D. S. dos Santos Jr, C. Blanco, J. C. Echeverria, J. J. Garrido, J. Colloid Interface Sci. 285, 41, (2005).

21. D. A. Kulik, S. U. Aja, V. A. Sinitsyn, S. A. Wood, Geochim. Cosmochim. Acta 64, 195, (2000).

22. K. S. Hui, C. Y. H. Chao, S. C. Kot, J. Hazard. Mater. 127, 89, (2005).

23. C. Özmetin, Ö. Aydın, M. M. Kocakerim, M. Korkmaz, E. Özmetin, Chem. Eng. J. 148, 420, (2009).

24. T. Motsi, N. A. Rowson, M. J. H. Simmons, Int. J. Miner. Process. 92, 42, (2009).

25. M. Doğan, M. Alkan, Chemosphere 50, 517, (2003).

26. M. Dogan, Y. Özdemir, M. Alkan, Dyes Pigments 75, 701, (2007).

27. B. A. Fil, C. Özmetin, J. Chem. Soc. Pakistan 34, 896, (2012).

28. C. H. Giles, D. Smith, A. Huitson, J. Colloid Interface Sci. 47, 755, (1974).

29. C. Hinz, Geoderma 99, 225, (2001).

30. G. Bayramoglu, B. Altintas, M. Y. Arica, Chem. Eng. J. 152, 339, (2009).

31. M. Alkan, Ö. Demirbaş, M. Doğan, Fresen. Environ. Bull. 13, 1112, (2004). 